\title{
El modelo biogenético y la bilateralidad parental en Colombia según los cambios generados por las técnicas de reproducción humana asistida
}

\author{
Olga Carolina Cárdenas Gómez* \\ Juliana Arias Escobar ** \\ Mariana Mendieta Montoya***
}

\begin{abstract}
RESUMEN
Este artículo busca explicar, mediante los cambios generados por las TRHA, la resignificación del modelo biogenético y la bilateralidad parental en Colombia como elementos tradicionales de atribución de la filiación. La metodología comprendió una revisión bibliográfica en temas de familia, filiación y reproducción asistida. También se realizaron entrevistas y grupos focales en los que se abordaron tres categorías: parentesco, modelo biogenético y bilateralidad parental. Los resultados permitieron identificar cuatro cambios (i) las alternativas para la reproducción que permiten "decidir" cómo convertirse en padres o madres; (ii) la mercantilización de la reproducción como respuesta a las decisiones que se toman en ejercicio de la autonomía reproductiva; (iii) las alternativas para la filiación representadas en la posibilidad de elegir ser padre/madre o, no serlo y, (iv) la diversidad parental como reconocimiento a las diversas formas que se emplean actualmente para construir parentesco. La conclusión se centra en la necesidad de reconocer elementos diferentes a la sangre al momento de atribuir la filiación como respeto a la diferencia y a la dignidad humana de los protagonistas de cada proyecto parental.
\end{abstract}

Modelo biogenético - bilateralidad parental - reproducción asistida

\section{The biogenetic attribution and the parental bilateralism in Colombia from changes generated by assisted reproduction technologies}

\section{Abstract}

This study examines the meaning of biogenetic parenthood attribution and parental bilateralism in Colombia as traditional elements that determine filiation, through the changes brought about

* Licenciada en Derecho, Universidad del Cauca, Colombia. Doctora en Derecho, Universidad de Laval, Quebec, Canadá. Docente investigadora, Departamento de Jurídicas, Facultad Ciencias Jurídicas y Sociales, Universidad de Caldas, Colombia. Correo electrónico: carolina.cardenas@ucaldas.edu.co

** Estudiante Programa de Derecho, Facultad Ciencias Jurídicas y Sociales, Universidad de Caldas, Colombia. Correo electrónico: juliana.511422524@ucaldas.edu.co

*** Estudiante Programa de Derecho, Facultad Ciencias Jurídicas y Sociales, Universidad de Caldas, Colombia. Correo electrónico: mariana.511421777@ucaldas.edu.co

Artículo recibido el 11 de agosto de 2018 y aceptado para su publicación en este número el 1 de agosto de 2019. 
by the enactment of ART. The methodology involved a biographic review, assessing the concept of family, filiation, and assisted reproduction. Furthermore a number of interviews and focus groups were completed that examined 3 features associated with kinship, the biogenetic parenthood model, and parental bilateralism. The following attributes were identified: (i) available alternatives associated with the act of reproduction that forgo the exclusively biological process and allows one to "elect" to become a parent; (ii) the commercialization of the reproduction process as one's rightful decision and autonomy to procreate; (iii) the alternatives to kinship that allows for the possibility of choosing to be a parent with or without a genetic link; and (iv) parental diversity as an acknowledgement of the various forms employed nowadays to establish kinship. The results of the study suggest that a mechanism other than blood is required to establish kinship, while recognizing the differences and dignity of the protagonists involved in each parenthood project.

Biogenetic parenthood model - parental bilateralism assisted reproduction tecnhnology

\section{INTRODUCCIÓN}

$\mathrm{E}$ 1 parentesco es un híbrido de dos hechos ${ }^{1}$ : uno natural o biológico y uno social. Según el hecho natural, el parentesco es la combinación de sustancia representada por los genes donde se unen sexualidad, procreación, vínculos parentales y filiación ${ }^{2}$. Los miembros relacionados entre sí son representados mediante la concepción nuclear de familia, es decir, aquella conformada por padre, madre e hijos. A partir de la reproducción, el parentesco establece una relación indiscutible entre la naturaleza y la cultura, debido a la imposibilidad de separar el estado de la naturaleza del estado de la sociedad ${ }^{3}$. La cultura utiliza entonces la naturaleza para establecer un orden nuevo ${ }^{4}$ en donde se han construido las bases de la sociedad occidental ${ }^{5}$.

Desde el punto de vista social, el parentesco implica un código de conducta, ya que permite identificar la posición de un individuo en la sociedad. Este también hace referencia a las relaciones humanas, generalmente de pertenencia ${ }^{6}$, que se desarrollan entre los parientes, así como las relaciones que se establecen con los demás, las que pueden ser de generosidad, temor u hostilidad ${ }^{7}$. Además, el parentesco permite dar cuenta de diversas "ideas, instituciones y prácticas que [tienen] que ver con la asignación de derechos y su transmisión de una generación a otra" 8 .

La concepción tradicional de parentesco está siendo, actualmente, cuestionada a partir de la incertidumbre que las diferentes prácticas sociales introducen al hecho biológico de la reproducción. Ejemplo de ellas son la adopción, los hijos de crianza y las técnicas de reproducción humana asistida (TRHA). Estas realidades sociales cuestionan

\footnotetext{
${ }^{1}$ SCHNEIDER, 1980.

2 RIVAS, 2009.

${ }^{3}$ LeVi-Strauss, 1985.

${ }^{4}$ LeVi-Strauss, 1985.

5 Levi-Strauss, 1985; Bestard et al., 2003.

${ }^{6}$ Bestard et al., 2003.

${ }^{7}$ Levi-Strauss, 1985.

${ }^{8}$ Bestard, 1998, p. 54.
} 
la bilateralidad parental y el modelo biogenético que hasta no hace mucho eran inamovibles ${ }^{9}$. Igualmente, la realidad social evidencia otras formas de organización familiar como las familias conformadas por parejas del mismo sexo, las familias reconstituidas y las familias monoparentales en donde la consanguinidad no resulta ser el hecho fundamental de las relaciones de parentesco.

\section{Metodología}

El objetivo del artículo es determinar, por medio de los cambios generados por las TRHA, la resignificación del modelo biogenético y la bilateralidad parental en Colombia. La metodología empleada durante la investigación fue plural. De una parte, se realizó una revisión de las leyes colombianas y la jurisprudencia de la Corte Suprema de Justicia desde 2013 respecto de familia, filiación y reproducción asistida. La revisión bibliográfica también comprendió el análisis de doctrina y artículos científicos. Esta revisión incluyó temas como el parentesco, las diversidades familiar y parental y las experiencias de las personas que han conformado sus familias por TRHA (con o sin intervención de terceros).

Este primer momento de la metodología permitió profundizar el concepto de familia y la designación acerca de quiénes son parientes. Los tipos de parentesco clásico (consanguíneo, por afinidad y civil o legal) revelan los elementos para determinar la maternidad y la paternidad. La familia se constituye entonces a partir del reconocimiento de dichos parentescos. No obstante, la realidad social evidencia que existen formas de organización familiar que no obedecen a dichos patrones.

De otra parte, se realizaron, durante el segundo semestre de 2017, dos grupos focales: un grupo focal de expertos conformado por tres profesionales en Desarrollo Familiar y un sociólogo cuyos intereses de investigación se concentran en enfoque de género, familia y género en dinámicas transnacionales y locales y teorías contemporáneas de la familia. El segundo grupo focal, conformado por cinco actores institucionales, permitió entablar un diálogo con un juez civil, un notario, dos defensores de familia del Instituto Colombiano de Bienestar Familiar y la representante de la Red nacional de mujeres capítulo Caldas. También se realizaron seis entrevistas semiestructuradas donde participaron 8 personas: dos antropólogas expertas en temas de parentesco, dos médicos especialistas en reproducción asistida, dos procuradores delegados para temas de familia de la Procuraduría General de la Nación, un juez civil y un notario. Esta parte empírica del proyecto se concentró en tres categorías: parentesco, modelo biogenético y bilateralidad parental.

En este segundo momento de la metodología, los discursos de los expertos, los diferentes actores institucionales, funcionarios públicos y los médicos posibilitaron identificar las categorías centrales, subsidiarias y emergentes de las categorías principales del proyecto. Como ejemplo, en la tabla 1 se muestras algunas de las categorías identificadas.

\footnotetext{
${ }^{9}$ Kemelmajer et al., 2014, p. 500.
} 
Tabla 1. Categorías conceptuales de análisis.

\begin{tabular}{|c|c|c|c|}
\hline $\begin{array}{l}\text { Categorías } \\
\text { principales }\end{array}$ & Parentesco & Modelo biogenético & Bilateralidad parental \\
\hline $\begin{array}{l}\text { Categorías } \\
\text { centrales }\end{array}$ & $\begin{array}{l}\text { Tipos de parentesco } \\
\text { Atribución del parentesco } \\
\text { Efectos del parentesco }\end{array}$ & $\begin{array}{l}\text { Concepción genético- } \\
\text { biologista } \\
\text { Reproducción sexual } \\
\text { Vínculo consanguíneo } \\
\text { entre padres e hijos }\end{array}$ & $\begin{array}{l}\text { Concepto de paternidad y } \\
\text { maternidad } \\
\text { Dualismo progenitor }\end{array}$ \\
\hline $\begin{array}{l}\text { Categorías } \\
\text { subsidiarias }\end{array}$ & $\begin{array}{l}\text { Derechos y obligaciones que } \\
\text { surgen en virtud del parentes- } \\
\text { co: alimentos, patria potestad, } \\
\text { herencia, prohibiciones }\end{array}$ & $\begin{array}{l}\text { Formas de organización } \\
\text { familiar: nuclear, mono- } \\
\text { parental, pluriparental, } \\
\text { coparental } \\
\text { Disociación entre vínculo } \\
\text { filial y conyugal }\end{array}$ & $\begin{array}{l}\text { Proyecto parental en solita- } \\
\text { rio o con varios progenitores }\end{array}$ \\
\hline $\begin{array}{l}\text { Categorías } \\
\text { emergentes }\end{array}$ & $\begin{array}{l}\text { Parentesco de facto: surge a } \\
\text { partir de la voluntad, el com- } \\
\text { promiso, el cuidado y el amor } \\
\text { Situaciones que cuestionan el } \\
\text { parentesco: gestación subroga- } \\
\text { da y la donación de gametos }\end{array}$ & $\begin{array}{l}\text { Legitimación de otras } \\
\text { formas de organización } \\
\text { familiar } \\
\text { Formas de emparentar } \\
\text { Disociación entre vínculo } \\
\text { jurídico y vínculo genético }\end{array}$ & $\begin{array}{l}\text { Construcción del parentesco: } \\
\text { los cambios culturales y las } \\
\text { experiencias de los actores } \\
\text { determinan cómo construir } \\
\text { o establecer el parentesco } \\
\text { Reconocimiento de nuevas } \\
\text { categorías de madre (biológi- } \\
\text { ca, genética y socioafectiva) } \\
\text { y padre (biológico-genético } \\
\text { y socioafectivo) }\end{array}$ \\
\hline
\end{tabular}

Estas diversas categorías permitieron identificar los cambios generados por las TRHA en el modelo biogenético y la bilateralidad parental en Colombia (Tabla 2). Estos cambios al cuestionar la concepción clásica de estos elementos del parentesco exigen una resignificación de los mismos entendida como la construcción de un concepto que permita reconocer otras fuentes de determinación del parentesco además de la consanguinidad y la adopción.

Tabla 2. Cambios sociales generados a partir de las TRHA.

\begin{tabular}{lc}
\hline \multicolumn{2}{c}{ Cambios sociales } \\
\hline Modelo biogenético & \multicolumn{2}{c}{ Bilateralidad parental } \\
\hline 1. Alternativas para la reproducción & 1. Alternativas para la filiación \\
\hline 2. Mercantilización de la reproducción & 2. Diversidad parental \\
\hline
\end{tabular}




\section{LA RESIGNIFICACión DEL MODELO BIOGENÉtico EN COLOMBia A PARTIR DE LAS TRHA}

La concepción tradicional de parentesco establece una conexión indisoluble entre sexualidad, procreación, alianza y filiación ${ }^{10}$ que garantiza la reproducción biológica, la continuidad del linaje y la garantía de la identidad ${ }^{11}$. Esta forma hegemónica de vincular a los hijos con sus progenitores se conoce como modelo biogenético ${ }^{12}$. Se entiende entonces que lo que determina la filiación es la sangre y que por medio de ella se legitiman "las relaciones sociales, filiales, conyugales y fraternales que se van extendiendo en forma ascendiente y descendiente" 13 . No obstante, en la actualidad, no todos los hijos son procreados biológicamente, es decir, mediante relaciones sexuales, ni sus padres son necesariamente los progenitores. Por ejemplo, en la adopción, la Ley 1098 de 2006 establece, mediante una ficción legal, la filiación entre personas que no guardan ningún vínculo genético entre sí ${ }^{14}$. En este caso, el parentesco surge a partir de la ley, no de la sangre, y lo que la ley hace es reconocer una decisión que se toma en ejercicio de la libertad ${ }^{15}$.

Actualmente el modelo biogenético y su utilidad para determinar quién es padre/ madre y quién es hijo ha dejado de ser el único elemento para determinar el parentesco. En palabras de Bestard: "la biología reproductiva deja de proporcionar modelos de certidumbre [considerados anteriormente], referente unívoco de las relaciones de parentesco"16. Los cambios sociales así lo demuestran ${ }^{17}$ En efecto, hoy se hacen visibles diversas alternativas para la reproducción en las que la reproducción biológica es solo una alternativa más. Adicionalmente, y como respuesta a las alternativas para la reproducción, se evidencia una "mercantilización" de la reproducción, entendida como la oferta de servicios que incluyen protocolos y medicamentos para tratar la infertilidad, intervenciones con fines reproductivos, donantes de gametos y embriones, gestantes subrogadas y congelamiento de gametos con el fin de postergar la paternidad/maternidad.

\section{Alternativas para la reproducción}

Tradicionalmente los hijos y su concepción han tenido una explicación sacramental. El Salmo 127, por ejemplo, alude a los hijos como una recompensa y señala que "[q]uien tiene muchos hijos, puede decir que Dios lo ha bendecido" ${ }^{18}$. En el caso contra-

\footnotetext{
${ }^{10}$ JOCILES Y Rivas, 2014.

11 BESTARD, 1998.

12 Bestard et al., 2003; Rivas, 2009.

13 Rivas, 2009, p. 9.

${ }^{14}$ Ley 1068 de 2006, art. 64.

15 BAptista, 1979.

${ }^{16}$ Bestard, 1998, p. 201.

${ }^{17}$ Pichardo et al., 2015.

${ }^{18}$ Salmo 127.
} 
rio, es decir, cuando las personas no pueden tener hijos, la infertilidad ha sido entendida como una prueba que se debe soportar porque "ninguna prueba os ha sobrevenido que no pueda considerarse humanamente soportable"19. Igualmente, la posibilidad de tener hijos en los casos de infertilidad era un milagro de Dios. En el libro del Génesis se relata que Isaac oró al Señor para que su mujer Rebecca, que era estéril, pudiera darle un hijo y el Señor lo escuchó ${ }^{20}$.

Esta visión sacramental de la procreación empezó a desacramentalizarse en 1978 cuando nace Louise Brown gracias a un procedimiento de fecundación in vitro ${ }^{21}$. Desde ese momento, los avances científicos en este campo han permitido "decidir" cómo ser padre o madre a partir del reconocimiento del derecho fundamental a la autonomía en materia reproductiva. Las TRHA representan un cambio social importante porque disocian la procreación de la sexualidad. Ser madre o padre ya no puede seguir ineluctablemente conectado a la naturaleza, donde el nacimiento de una nueva vida era inmediatamente relacionado con el desempeño sexual anterior de un hombre ${ }^{22}$.

Esta concepción heteronormativa del parentesco no ha sido ni única ni universal. Debe recordarse que la representación de la familia como la familia nuclear solo tomó fuerza durante el siglo XVIII ${ }^{23}$. No obstante, dicha forma de organización familiar ha sido fruto de diversas críticas en virtud de la desigual distribución del trabajo entre hombres y mujeres ${ }^{24}$, la desigualdad interseccional entre raza, clase y género ${ }^{25}$ y los cambios a nivel de convivencia y estructura familiar (parejas que conviven sin casarse, hijos extramatrimoniales, divorcios, madres/padres solteros $)^{26}$.

Igualmente, debe mencionarse que desde la Antropología también se ha cuestionado el principio binario imperante en las ciencias sociales en temas de género y sexualidad. En efecto, ello ha implicado, de una parte, que la única sexualidad válida sea la reproductiva, es decir, aquella mantenida entre personas heterosexuales, lo que estigmatiza las prácticas entre personas del mismo sexo ${ }^{27}$. De otra parte, la identidad de género se asume desde ciertas características del cuerpo, es decir, que un cuerpo biológicamente femenino tendrá que desarrollar una identidad de género femenina. Sin embargo, la variabilidad de la morfología genital humana ha llevado a autores como Buttler a cuestionar la concepción natural del sexo al afirmar que este está tan culturalmente construido como el género ${ }^{28}$.

\footnotetext{
191 Corintios 10:13.

${ }^{20}$ Génesis 25:21.

${ }^{21}$ Steptoe y Edwards, 1978.

22 Baptista, 1979.

23 Castillo, 2015.

${ }^{24}$ Beck-Gernsheim, 1998.

25 HartmanN, 2000.

26 Montencino, 2007.

27 Maristany, 2008.

28 Buttler, 2007.
} 
La disociación procreación/sexualidad y los cuestionamientos al principio binario en materia de género y sexualidad abren una variedad de opciones para personas que por condiciones de salud o plan de vida tendrían excluida la posibilidad de tener hijos. Las parejas heterosexuales infértiles, las parejas del mismo sexo y las mujeres u hombres que desean construir un proyecto familiar en solitario (padre e hijo(s) o madre e hijo(s) ${ }^{29}$ ven en las TRHA una opción que les permite materializar el deseo de tener un hijo. En efecto, el cambio producido por las TRHA y, particularmente, por las TRHA con intervención de donante de gametos o de embriones permite ser madre o padre sin que exista necesariamente contacto sexual.

Adicionalmente, en las TRHA no resulta relevante el género como sucede en la reproducción sexual. En efecto, las parejas del mismo sexo, al igual que las parejas heterosexuales, construyen proyectos de vida que en ocasiones incluyen hijos. Pichardo et al. señalan al respecto que

[S]i ya se habían dado los cambios sociales que permitieron desvincular la sexualidad de la reproducción y la reproducción de la sexualidad, la mayoría de las personas no heterosexuales han profundizado esta ruptura al acceder a la parentalidad (maternidad y paternidad) por vías alternativas a la relación coital heterosexual. Se incide así en la idea de que ni la sexualidad ni la reproducción van a ser ni exclusivamente coitales ni heterosexuales" 30 .

Ahora bien, debe reconocerse que si bien las TRHA permiten a las parejas homosexuales materializar su proyecto parental, esto no implica que la maternidad o la paternidad no sea construida en un contexto heteronormativo y, muchas veces, homofóbico $^{31}$. La experiencia de parejas gays en Chile revela que ellos se ven forzados a construir su paternidad en un contexto que devalúa sus capacidades como padres y estigmatiza y discrimina su identidad sexual. En ese contexto, estas parejas deben superar importantes barreras culturales que impiden no solo el ejercicio sino el acceso a la paternidad ${ }^{32}$.

Ahora, si bien las TRHA ofrecen una alternativa para la reproducción, ellas refuerzan, en muchos casos, el peso simbólico de la sangre en virtud de los intereses que motivan a las personas a recurrir a los centros de reproducción asistida (CRA). Asimismo, las TRHA consolidan el proyecto de la familia completa, entendida como la familia nuclear, ya que ellas permiten responder al deseo de transmisión de la información genética a la descendencia y, en esa medida, aseguran la identidad del hijo.

Desde una perspectiva opuesta, la intervención de terceras personas (donantes o gestantes subrogadas) en la materialización de un proyecto parental amplían las opciones en materia de reproducción. En efecto, las personas pueden recurrir a los donantes

\footnotetext{
29 IMAX, 2006.

${ }^{30}$ Pichardo et al. (2015), p. 188.

${ }^{31}$ Herrera et al., 2018a.

${ }^{32}$ Herrera et al., 2018a.
} 
en los casos de transmisión de enfermedades genéticas, de características indeseadas o de problemas con sus gametos. Igualmente, las parejas pueden recurrir a la gestación subrogada en los casos en los que es imposible llevar un embarazo a término por limitaciones fisiológicas (parejas gays) o por problemas de salud ${ }^{33}$.

Los argumentos identificados en las fuentes secundarias coinciden con lo observado en los grupos focales y las entrevistas. En el grupo focal de expertos se insistió acerca de la visión sacramentalizada de la reproducción, ya que socialmente aún se considera que los hijos son un regalo de $\operatorname{Dios}^{34}$. También se evidencia que los hijos deben estar vinculados a los padres genéticamente, lo que permite comprender que en la reproducción asistida circule también el discurso referido al "valor de la sangre, ya que esta es lo que más peso tiene en la conexión entre las personas"35. Además, los expertos insisten en que las emociones juegan un papel trascedente dentro de las relaciones familiares y sociales junto con la carga genética, ya que "existe el deseo del hijo propio, lo que activa una dimensión simbológica de decir este hijo es mío" 36 . Esta idea es compartida también por uno de los entrevistados que manifestaba al respecto que "el semen [y] el óvulo [tienen] una carga genética y en nuestra cultura [esta] representa una transmisión de rasgos fenotípicos que para nosotros forma parte de la construcción del parentesco. Que yo me parezca a mi padre forma parte de mi identidad, y no solamente para mí, sino para los demás"37.

El necesitar vernos reflejados en nuestros parientes por medio de los rasgos fenotípicos explicaría, según uno de los participantes en el grupo focal de expertos, por qué "las parejas heterosexuales gastan una fortuna en la reproducción asistida para poder tener un hijo propio"38. Igualmente, esta decisión responde a una "exigencia social acerca de cómo y de qué manera ese hijo responde al genotipo de la familia, es decir, qué tan parecido es a sus padres" o en palabras más coloquiales, cómo mediante el hijo se reconoce la "pinta" de sus padres ${ }^{39}$. La importancia acordada a la sangre en las relaciones sociales y familiares hace que cualquier otra opción distinta a la sangre empiece a cuestionarse con afirmaciones como "es que es tan difícil cuando no es de la misma sangre”, haciendo referencia a las dificultades que se pueden presentar en el proceso de crianza y cuidado de los hijos adoptivos ${ }^{40}$.

No obstante, en el grupo focal de expertos se reconoció, como se ha evidenciado en las fuentes secundarias, que las TRHA se han convertido en una alternativa que permite a las parejas del mismo sexo tener hijos. Uno de los participantes en el grupo focal de expertos manifestaba que "cuando se pregunta a las parejas del mismo sexo respecto de su deseo de ser padres, ellos dicen que sí les gustaría ser padres pero que no quieren

\footnotetext{
33 Delaisi y Collard, 2007.

${ }^{34}$ Grupo Focal 1.

35 Grupo Focal 1.

${ }^{36}$ Grupo Focal 1.

37 Entrevista 4.

38 Grupo Focal 1.

39 Grupo Focal 1.

${ }^{40}$ Grupo Focal 1
} 
tener una relación sexual con una mujer o con un hombre. Dicen que ellos desean una fecundación o un proceso de adopción" ${ }^{41}$. Si bien en nuestras sociedades aún existen posiciones que discriminan y cuestionan la existencia de estas parejas y su decisión de ser padres, uno de los entrevistados señalaba que "no es contra natura que las parejas homosexuales deseen desarrollarse como pareja y como familia y quieran tener descendencia. Eso es un derecho" ${ }^{42}$.

Finalmente, dentro del grupo focal con los expertos también se abordó un tema de la reproducción asistida que poco se discute en la doctrina. Se trata de la "dimensión pública de la reproducción”, entendida como la intervención de terceros en la materialización de algunos proyectos parentales. En esa medida, la reproducción no puede seguir pensándose como algo íntimo y familiar ${ }^{43}$. Además, las TRHA necesitan el apoyo de profesionales de salud con quienes se discuten abiertamente las intervenciones posibles, las tasas de éxito, así como las recomendaciones a tener en cuenta en la vida sexual de la pareja ${ }^{44}$. Según Noel y Flores, en la reproducción asistida "la procreación pierde su dimensión sentimental, sexual e íntima porque [esta] se hace con cierta publicidad e intervención de varias personas que constituyen un equipo especializado" ${ }^{4}$.

Las TRHA, como se observa, ofrecen diversas alternativas para la materialización de un proyecto parental. No obstante, dichas alternativas no pueden estar al alcance de las personas que desean hacer uso de ellas sin que se produzca un cambio concomitante entendido como la garantía de acceso a las TRHA. La mercantilización de la reproducción, al margen de toda connotación moral, es uno de los cambios que permite asegurar que las decisiones que se tomen en materia reproductiva se puedan concretar.

\section{Mercantilización de la reproducción}

En una dinámica de mercado, las TRHA responden a la demanda realizada por personas o parejas que desean ser padres y que no logran conseguirlo mediante la reproducción sexual. Para responder a esa demanda los profesionales en reproducción ofrecen diversas posibilidades que van desde protocolos para facilitar la procreación hasta intervenciones de alta complejidad. Estos servicios han dado lugar al término "bioeconomía reproductiva" 46.

Actualmente existe un "mercado globalizado de la reproducción" ${ }^{77}$ conformado por CRA y bancos de gametos o embriones. Estos últimos ofrecen la venta de pajillas en línea y su entrega a domicilio a centros o a particulares de diferentes países. En el caso particular de la venta de pajillas con semen de donante, el valor de cada una de

\footnotetext{
${ }^{41}$ Grupo Focal 1.

42 Entrevista 2.

43 Grupo Focal 1.

${ }^{44}$ Entrevista 2.

45 Noel y Flores, 2012, p. 30.

${ }^{46}$ KROL ØKKe et al., 2012.

${ }^{47}$ Déchaux y Darius, 2017 p. 425.
} 
ellas depende de factores como la calidad del semen, los procedimientos de preparación del mismo, el tipo de conservación, el volumen demandado y la información solicitada del donante ${ }^{48}$.

Los CRA pueden optar por el anonimato o la revelación de la identidad del donante. Quienes aseguran el anonimato, es decir, la imposibilidad de revelar la identidad de quienes participan en la TRHA con gametos o embriones de donante buscan proteger la intimidad y la vida privada de los donantes. También se busca proteger los derechos a conformar una familia y al respeto de la vida privada de quienes acuden a la TRHA.

Los CRA pueden también revelar la identidad del donante. Sin embargo, esta opción, que ha sido acogida en muchas legislaciones (v.g. Inglaterra, Suecia y Alemania), es desaconsejada porque el número de donantes disminuye considerablemente. De hecho, según la BBC, en 2015, desde la inauguración del banco nacional de esperma de Reino Unido en octubre de 2014 solo 9 donantes se habían registrado en un año de funcionamiento ${ }^{49}$. La baja tasa de donaciones fue atribuida a la eliminación del anonimato de los donantes en Inglaterra desde el 2005. Un año más tarde, la BBC Mundo publicó que el banco había dejado de funcionar debido a la baja tasa de donaciones (solo logró recepcionar 7 donantes efectivos) y a las dificultades financieras para mantenerlo en funcionamiento ${ }^{50}$.

La donación de gametos también se moviliza políticamente y tiene impactos relacionados con el género, el aumento de la natalidad y la preservación de la raza ${ }^{51}$. Igualmente, ella tiene impactos económicos no solo porque permiten a la mujer aplazar la maternidad durante la edad fértil, sino también, como se mencionó, permite la mercantilización de gametos, células y tejidos ${ }^{52}$.

Los CRA también ofrecen servicios de congelamiento de gametos con el fin de hacer una reserva para el futuro. Gracias a esta opción, las mujeres son las más beneficiadas porque pueden elegir cuándo ser madres a pesar de que la etapa conocida como edad fértil se sobrepase ${ }^{53}$. Las mujeres entonces no se ven en la obligación de ser madres entre los 25 y los 35 años, sino que pueden congelar sus óvulos y solicitar que sean fecundados y transferidos cuando lo estimen más conveniente sin preocuparse por la posibilidad de transmitir a sus hijos enfermedades genéticas cuya probabilidad de transmisión aumenta con la edad (v.g. síndrome de Down).

La mercantilización de la reproducción también permite ofrecer servicios de gestación subrogada. Las instituciones dedicadas a prestar este servicio poseen "catálogos en los que se muestran fotografías de las posibles madres disponibles con información específica de cada una de ellas: historial médico de la posible gestante, raza, origen, religión, estudios cursados y rasgos de la personalidad" 54 .

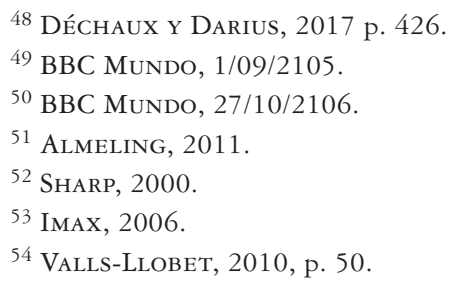


Esta práctica se revela compleja para los legisladores, debido a las opiniones contrarias que existen acerca de ella. En efecto, existen posiciones a favor de reconocerla como una práctica lícita siempre y cuando se realice sin fines de lucro ${ }^{55}$. No obstante, la mayoría de las críticas son en contra porque se considera que ella permite la explotación de mujeres en condiciones de vulnerabilidad/pobreza, el aumento de las desigualdades y la cosificación de la maternidad, ya que la mujer se convierte en un medio para satisfacer intereses particulares de terceras personas. Igualmente, los opositores de la gestación subrogada consideran que ella posibilita la mercantilización de la filiación ${ }^{56}$, el fraude a las normas de adopción y la supresión de la identidad ${ }^{57}$.

Si bien la gestación subrogada no ha sido regulada en muchos países (v.g. Colombia) o ha sido prohibida (v.g. Francia y España), algunos países la permiten, y de entre ellos, un cierto número permite que los contratos celebrados entre la gestante y los comitentes tenga ánimo de lucro (v.g. Estados Unidos, México, India, Tailandia, Georgia). Rubio señala que permitir este tipo de contratos "supone un beneficio para todas las partes que intervienen este tipo de práctica [ya que] satisface los deseos de dos familias: una se llevará a casa el hijo largamente esperado [y] la otra, el dinero que no ganará ni en 15 años de trabajo" 58. Además, para ciertos autores "[1]a gestación por sustitución no viola el interés superior del niño debido a que el niño nace en una familia que lo deseó y [que él no existiría] de no haberse recurrido a [ella]" 59 .

Finalmente, la mercantilización de la reproducción genera dos dilemas importantes: el acceso a las TRHA en condiciones de igualdad y el turismo reproductivo. Lastimosamente, el costo de las intervenciones y los límites de los planes de salud hacen que solo algunas personas puedan tener acceso a tratamientos de reproducción asistida de alta complejidad. Esta afirmación fue reiterativa entre diversos participantes ${ }^{60}$. Sin embargo, los CRA proponen una solución. Los médicos entrevistados mencionaban que ciertos CRA ofrecen "planes" o "paquetes" de servicios que incluyen 3 o 4 ciclos. De esta forma se reduce el estrés a la paciente, quien, de lo contrario, tendría la preocupación de qué hacer en caso de que en el primer ciclo no logre embarazarse. De esta forma se asegura un segundo y un tercer intento ${ }^{61}$. Adicionalmente, cuando la oferta de servicios en un país entra en conflicto con los intereses particulares, las personas buscan evadir las limitaciones impuestas y, generalmente, se desplazan de un país a otro. Este fenómeno conocido como turismo reproductivo ${ }^{62}$ ha sido definido como el desplazamiento

\footnotetext{
55 LÓPEZ Y APARISI, 2012.

56 LÓPEZ y APARISI, 2012.

${ }^{57}$ LAMM, 2012.

58 Rubio, 2012, p. 68.

59 LAMM, 2012, p. 10.

${ }^{60}$ Grupos focales 1 y 2; Entrevistas 2 y 4 .

61 Entrevista 2.

${ }^{62}$ Knoppers y LeBris, 1991.
} 
de una persona de una institución o país donde no está disponible el tratamiento de reproducción asistida que necesita a otra institución o país donde puede obtenerlo ${ }^{63}$.

Inhorn y Pasquale plantean que el término "turismo reproductivo" debe ser replanteado porque el turismo está relacionado con el descanso, el placer y las vacaciones ${ }^{64}$. Para estos autores, cuando una pareja se ve obligada a viajar en busca de una solución que les permita materializar su proyecto parental debe hablarse más bien de "exilio reproductivo”. Esta terminología podría representar mejor la situación que viven los pacientes que se enfrentan a exigencias físicas, emocionales y, en ocasiones, económicas para recibir los servicios que necesitan.

En las entrevistas realizadas, los médicos señalaron que el mercado ofrece actualmente servicios como la inseminación artificial, la transferencia intratubárica de gametos, la fecundación in vitro (FIV), la transferencia intratubárica de cigotos y la inyección intracitoplasmática de espermatozoides (ICSI); el congelamiento de gametos y embriones y la donación de gametos y de embriones, entre otros. A esto se suma la posibilidad de suscribir contratos de gestación subrogada y la garantía del anonimato para asegurar el flujo de donantes ${ }^{65}$.

Los médicos entrevistados explicaron que, en cada caso, se elabora un protocolo escalonado que se inicia con intervenciones sencillas para mejorar las probabilidades naturales. Dichas intervenciones se hacen complejas según las particularidades de los pacientes. Los entrevistados manifestaron que "del 20\% de personas que consultan, el 80 o el $90 \%$ solucionan sus problemas con técnicas no avanzadas, entonces, esos pacientes pueden obtener medicamentos, tratamientos de ovulación, corregir problemas ováricos, es decir, que a muchas parejas se les trata de solucionar los problemas sin necesidad de llegar a las técnicas de alta complejidad"66. Sin embargo, en esta etapa también se puede ofrecer de manera directa una técnica de alta complejidad para aumentar la tasa de embarazo. En estos casos, los médicos mencionaron que los pacientes son informados acerca de la posibilidad de lograr un embarazo más fácilmente, elemento clave en la decisión final que ellos van a tomar. No obstante, la recomendación, desde la ética médica, es tratar de restablecer la fertilidad natural, con el fin de que las parejas puedan lograr un embarazo de manera natural ${ }^{67}$.

Cuando esta primera intervención no da resultado, es decir, no se logra el embarazo, se procede a ofrecer técnicas más complejas o específicas como la inseminación artificial, la FIV o la ICSI. Los entrevistados señalaron que en el caso de la ICSI, el CRA puede garantizar en $100 \%$ la fecundación, mientras que en el caso de la FIV, la tasa de fecundación es del $80 \%$. Sin embargo, cuando la calidad del semen o del óvulo no es buena

\footnotetext{
63 Pennings, 2002.

${ }^{64}$ INHORN y PASQUALE, 2009.

65 Entrevista 2.

66 Entrevista 2.

${ }^{67}$ Entrevista 2.
} 
o cuando la reserva ovárica es baja o nula, la recomendación es recurrir directamente a la donación de gametos ${ }^{68}$.

Si bien la doctrina señala que la donación de gametos es altruista ${ }^{69}$, en la práctica los donantes son compensados económicamente. El valor de la compensación varía para los donantes de semen y las donantes de óvulos ${ }^{70}$. No obstante, esta compensación no se puede considerar como un pago, ya que ello contrariaría las normas que permiten la disposición del cuerpo de forma gratuita.

La donación de gametos, al menos en Colombia, es anónima, porque, como se explicó, esto permite asegurar el flujo de donantes por el temor de muchos de ellos de ser demandados en el futuro ${ }^{71}$. Asimismo, el anonimato impide el ejercicio abusivo de acciones de investigación de la paternidad de parte del donante o del hijo concebido con sus gametos. Esta es una preocupación importante si se tiene en cuenta que una prueba de ADN sería suficiente para establecer un vínculo filial desde una perspectiva netamente biológica, a causa de la ausencia de legislación en Colombia respecto de la filiación por TRHA.

Igualmente, en los grupos focales y las entrevistas se insistió en que la mercantilización de la reproducción obedece a una dinámica global que cubre no solo la oferta de servicios sino también la circulación internacional de gametos ${ }^{72}$, como se mencionó. Además, en el caso de la gestación subrogada, "la dispar regulación de los derechos nacionales motiva que estos acuerdos se celebren entre personas situadas en países distintos, abarcando en la práctica los lugares más distantes del mundo"73.

La mercantilización de la reproducción no se podría considerar completa en ausencia de una orientación jurídica que permita evitar problemas en el futuro. Los CRA cuentan con asesores jurídicos que garantizan que las decisiones que se toman sean legales. Los médicos entrevistados destacaban que la función principal de estos profesionales es asegurar que quienes acceden a las TRHA sean reconocidos como padres y, en consecuencia, sean ellos quienes asumen los derechos y responsabilidades que implica la paternidad o la maternidad ${ }^{74}$.

A pesar de los esfuerzos hechos por entrevistar abogados que trabajen en este campo, ninguno de los profesionales invitados a participar respondió afirmativamente a la invitación. Esta negativa podría ser explicada desde diferentes perspectivas: primero, la ausencia de legislación en Colombia, lo que permite ofrecer las TRHA sin límites o prohibiciones diferentes a las que se imponen los mismos CRA. Segundo, el peso de una cultura influenciada por valores religiosos cristianos, donde el concepto de familia nuclear sigue predominando. Finalmente, la necesidad de mantener la discreción y confidencialidad acerca de sus actividades con el fin de no atraer la atención social.

\footnotetext{
68 Entrevista 2.

69 Jociles, 2016.

${ }^{70}$ Entrevista 2.

71 Entrevista 4.

72 Grupo focal 1.

73 ScOTті, 2012, p. 276.

${ }^{74}$ Entrevista 2.
} 
Esto se explica, según Morgan, porque mientras los casos no sean públicos o numerosos no existirá presión para regularlos ${ }^{75}$. En esa medida, cada abogado es libre de proponer soluciones a partir de su interpretación de las leyes existentes. Sin embargo, desde el momento en que se evidencia la necesidad de regular el tema, los abogados, los operadores jurídicos y los legisladores deberán reglamentar los límites aceptables según los objetivos particulares de cada sociedad ${ }^{76}$.

El modelo biogenético como elemento del parentesco no es un único que se ve cuestionado por estos cambios. La bilateralidad parental se ve igualmente interrogada, ya que las TRHA crean nuevas formas de establecer la filiación y en esa medida los conceptos clásicos de padre, madre y filiación resultan insuficientes para abarcar la diversidad parental que se presenta.

\section{LA RESIGNIFICACIÓN DE LA BILATERALIDAD PARENTAL EN COLOMBIA DEBIDO A LAS TRHA}

La bilateralidad parental ha sido entendida como el proceso de vinculación paterna y materna de carácter bilateral y bidireccional entre dos sujetos ${ }^{77}$ caracterizada por la dualidad parental. Las TRHA, al igual que ocurrió con la adopción, están cuestionando la bilateralidad parental debido a la intervención de donantes o gestantes subrogadas en el proyecto parental. Actualmente existen diversas alternativas para la filiación en la medida en que los padres no siempre son biológicos o genéticos y que quienes aportan sus gametos no se convierten necesariamente en padres. Esta situación está dando origen a una diversidad parental que reconoce diversas formas de parentesco y de organización familiar.

\section{Alternativas para la filiación}

Los cuestionamientos al modelo hegemónico de parentesco evidencian que este no se establece solamente a partir del vínculo biológico. "Esta situación está creando una distinción entre parentesco y parentalidad". Ciertamente, "la parentalidad es un hecho cultural que acaece en un proceso de construcción y de definición social acerca de lo que se considera qué es la paternidad y la maternidad. Ambas realidades, paternidad y maternidad, se construyen en el entramado de las relaciones sociales" 78 .

Las TRHA, principalmente aquellas donde terceros intervienen en el proyecto parental, disocian no solamente la procreación de la filiación, sino también el parentesco de la parentalidad. Según Bestard, "las disputas en torno a las definiciones de la

\footnotetext{
75 Morgan y Lee, 1998.

76 Morgan y Lee, 1998.

77 Romero, 2007.

${ }^{78}$ Romero, 2007, pp. 120-121.
} 
paternidad y la maternidad que hoy se producen en el contexto de las tecnologías de procreación asistida no parecen poder solucionarse mediante referencias a la naturaleza de los hechos de la vida"79. Palacio y Cárdenas señalan al respecto que "[1]a monoparentalidad o la pluriparentalidad evidencian la insuficiencia del modelo biogenético para atribuir el parentesco. De un modelo basado en el reconocimiento de los lazos de sangre y la vinculación genética se pasa a la construcción social del parentesco" ${ }^{80}$. En efecto, la realidad social deja en evidencia que la filiación no solo se debe determinar a partir de la genética, sino que también se debe reconocer la voluntad como elemento creador y de legitimación del vínculo social.

Para Baptista, "la paternidad no es en sí un hecho de la naturaleza sino un hecho cultural" ${ }^{81}$. En efecto, ante el nacimiento de una persona, el padre y la madre pueden comportarse de diversas formas que pueden ir desde la acogida hasta el rechazo ${ }^{82}$. La decisión, por tanto, de ser madre o padre se toma y la maternidad o la paternidad se construyen $^{83}$. El papel de padre puede entonces diferenciarse entre quién es verdaderamente padre y quién es progenitor. Para Lamm, "padre es aquel, que [...] asume dicha función social, aunque sanguíneamente el patrimonio genético del hijo no lleve su impronta, mientras que progenitor es aquel que simplemente aporta el material genético sin pretender ninguna relación jurídica con el ser que nazca" ${ }^{4}$. El progenitor debe en consecuencia ser liberado de asumir un papel que no ha deseado para reconocérselo a quien lo deseó.

La disociación entre padre/madre y progenitor/progenitora ha dado lugar al reconocimiento de la paternidad y la maternidad socioafectiva en la que "[s]entirse y ser tratado como hijo implica el legítimo reconocimiento de una verdad que no puede ocultarse [y] de una paternidad [o maternidad] que se vive y se siente" ${ }^{25}$. El fundamento de estas parentalidades no se encuentra entonces en lo biológico sino en la autonomía decisional, la voluntad y el afecto ${ }^{86}$. De hecho, Kemelmajer et al. señalan que el elemento volutivo debe ocupar un espacio de mayor envergadura que el componente genético, porque el niño nace gracias a la manifestación de la voluntad, y es precisamente esa voluntad la que permite a esa persona acceder a la paternidad ${ }^{87}$.

Según Bestard, si bien la filiación nos une con nuestros ascendientes y nuestros descendientes, la intencionalidad nos permite hablar de un deseo de descendencia ${ }^{88}$. Donar un óvulo no establece entonces, automáticamente, un vínculo entre quien dona y

\footnotetext{
79 Bestard, 1998, p. 201.

${ }^{80}$ Palacio y Cárdenas, 2017, p. 59.

81 BAPTISTA, 1979, p. 401.

82 Baptista, 1979.

83 Puyana, 2003.

${ }^{84}$ LAMM, 2013, p. 51.

85 VARsi, 2010, p. 57.

86 VARSI, 2017.

${ }^{87}$ Kemelmajer et al., 2010.

88 Bestard, 2009.
} 
quien nace de ese gameto. El vínculo surge por medio de la intencionalidad o del deseo con el que se construye el proyecto parental. El elemento constitutivo de la filiación no es entonces la consanguinidad sino el deseo de parentalidad ${ }^{89}$. Pesino comparte esta visión al señalar que "[n]o se puede afirmar [...] que para determinar la filiación, baste solo el criterio biológico. El hijo que está en gestación está ya inscripto en una cadena de deseos" 90 .

La filiación no puede, entonces, seguirse pensando desde un determinismo biológico sino desde la "construcción afectiva permanente que se hace en la convivencia y en la responsabilidad”91. Por ello ante la pregunta: ¿Cómo establecer la conexión con un ser que no se procrea? La respuesta debe ser mediante la voluntad reproductiva que es "la causa eficiente última e infungible, porque los demás elementos, biológicos y/o genéticos, pueden ser sustituidos [es decir,] la aportación de todos los demás protagonistas es fungible y no es verdadera causa eficiente (en sentido vivencial y ontológico) del nacimiento" 92 .

La voluntad procreativa también tiene una cara opuesta. Esta está representada por la decisión del donante de gametos o de la gestante subrogada de no tener ningún vínculo con el niño que nace a partir de sus gametos o que gesta. En efecto, ellos no piensan en los niños como sus hijos. Además, en las legislaciones que permiten conocer la identidad del donante, la misma ley establece que los donantes o las gestantes y los niños no pueden establecer ninguna relación filial. En Colombia, la Corte Suprema de Justicia ha optado por la misma posición. En un caso fallado en el 2013, la Sala Civil se pronunció por la imposibilidad de establecer un vínculo filial con un donante anónimo ${ }^{93}$.

A pesar de diferencia entre progenitor y padre/madre, la legislación colombiana aún determina la filiación a partir de la existencia de un vínculo biológico o legal (en el caso de la adopción). Desde esa perspectiva, la filiación por TRHA preocupa desde dos aspectos: primero, el reconocimiento de su determinación y, segundo, el ejercicio de derechos ( $v . g$. alimentos, custodia, visitas, patria potestad y herencia) por los sujetos a quienes ella vincula. En el primer caso es necesario reconocer las TRHA como una fuente filial autónoma con reglas distintas a las de la filiación biológica o adoptiva ${ }^{94}$. Para Herrera et al., esto se explica por la ausencia en las TRHA de una concepción por medio de una relación sexual, lo que genera conflictos diferentes de los surgidos en el marco de la filiación biológica o adoptiva. La biotecnología permite la criopreservación de gametos y embriones por periodos prolongados, donde puede cambiar el deseo de ser padres y la situación de la pareja y las TRHA permiten disociar los elementos biológico, genético y volitivo dándole prevalencia a este último respecto de los dos primeros ${ }^{95}$.

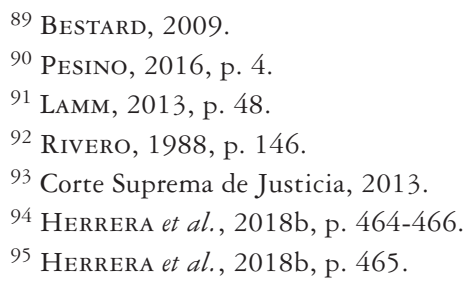


Las modificaciones en la legislación concernientes a determinación de la filiación por TRHA deben reconocer como factor de atribución la voluntad procreativa y el consentimiento libre e informado tal como ha ocurrido en Argentina ${ }^{96}$. En esa medida, los resultados de la prueba de $\mathrm{ADN}$, considerados fundamentales en los procesos de filiación ${ }^{97}$, quedan relegados por ausencia de objeto, particularmente en las TRHA heterólogas. La Corte Suprema de Justicia colombiana tuvo la posibilidad de pronunciarse al respecto en un caso de impugnación de la paternidad de dos menores concebidas mediante inseminación artificial con semen de donante ${ }^{98}$.

Ahora bien, si la igualdad entre los hijos debe mantenerse en virtud de lo dispuesto en el artículo 42 de la Constitución Política, dicha igualdad debe ser material, no formal. En otras palabras, debe existir un tratamiento diferente entre los hijos según su origen filial con miras a proteger su interés superior. Por ejemplo, debe limitarse el ejercicio de las acciones de impugnación o investigación de la paternidad como mecanismo para asegurar la estabilidad del estado civil como ocurre en España ${ }^{99}$. Igualmente, debe revisarse el ejercicio de la acción de petición de herencia, principalmente en los casos de fecundación post mortem, ya que la Ley $\mathrm{N}^{\circ} 75$ de 1968 prevé efectos patrimoniales a las acciones de investigación notificadas a los herederos dentro de los dos años siguientes a la muerte del pretenso padre. También se debe analizar el ejercicio del derecho a conocer los verdaderos orígenes biológicos reconocidos en al artículo 25 de la Ley $\mathrm{N}^{\mathrm{o}} 1098$ de 2006, debido a que el origen biológico es tan solo una de las fuentes de la filiación. Dentro de este análisis es clave tener en cuenta que el ejercicio de este derecho, como todos los otros derechos, no es absoluto ${ }^{100}$.

Los hallazgos encontrados en la doctrina coinciden con los discursos de los grupos focales y las entrevistas. Para empezar, resulta claro que parentesco y parentalidad no son términos sinónimos. Una de las expertas entrevistadas señalaba que por parentesco debe entenderse el vínculo biogenético sancionado por la ley, mientras que la parentalidad hace referencia al ejercicio de los roles atribuidos tradicionalmente al padre y la madre ${ }^{101}$. En esa medida, las TRHA permiten establecer el vínculo a partir del deseo del otro y de las emociones a pesar de que terceras personas hayan contribuido a su procreación $^{102}$. Sin ese deseo, el niño nunca hubiese nacido. En consecuencia, el papel de padre o madre debe atribuirse a quien tiene la intención de cuidar al niño. De ahí que para algunos de los entrevistados cuando el donante y el niño tienen la posibilidad de conocerse, la relación que entablan no equivale a una relación con derechos y deberes como aquella que surge del parentesco, ya que los verdaderos padres son los padres de

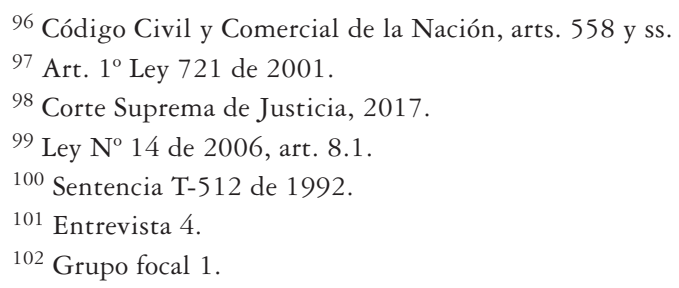


intención ${ }^{103}$. Igual sucede con la gestación subrogada. En esos casos, una de las personas entrevistadas manifestaba que las gestantes se ven como "cuidadoras o portadoras de un niño que es para otra persona o para otra pareja"104. De hecho, la experta insistía en que ellas se conciben "como aquellas que han hecho posible satisfacer el deseo de los hijos de otros ya que madre es la que va a criar, a educar, a cuidar" 105 .

Las alternativas para la filiación tienen finalmente, como cambio, un efecto importante en la bilateralidad parental a causa de la dificultad que tenemos para pensar en términos plurales. Gracias a las TRHA con gametos de donantes o a la gestación subrogada, un niño puede tener varios padres/madres a partir de los elementos biológicos y de los elementos volutivos que no pueden ser desconocidos.

\section{Diversidad parental}

La disociación generada por las TRHA con donantes y gestantes subrogadas evidencian diversas parentalidades como la maternidad y la paternidad genética, la maternidad biológica y la maternidad y paternidad social ${ }^{106}$. Así, la esposa o compañera no siempre es madre genética (quien aporta los óvulos) ni madre biológica (quien lleva el embarazo a término), a pesar de que ella va a ser la madre social o de intención (quien cuida y cría). En el caso del esposo o compañero, este no siempre es padre biológico o genético (quien aporta los gametos), si bien puede llegar a ser el padre social o de intención ${ }^{107}$.

Esta diversidad de parentalidades hace que actualmente se hable de monoparentalidad en los casos en que mujeres u hombres desean, de forma individual, convertirse en madres o padres ${ }^{108}$. Igualmente se habla de pluriparentalidad cuando uno o dos progenitores contribuyen a la materialización del proyecto parental pero el proceso de crianza y cuidado del niño es asumido por terceros o cuando los padres biológicos separados o divorciados desean involucrar a su nueva pareja en el proceso de cuidado y crianza de los hijos como sucede en el caso de las familias reconstituidas o ensambladas ${ }^{109}$. En el caso de la gestación subrogada, Lamm señala que "[1]a aportación del gameto femenino, la gestación, el deseo, la voluntad de ser madre y la atribución de la función jurídicosocial de madre pueden corresponder a diferentes mujeres o concurrir algunas de estas funciones en una mujer" ${ }^{110}$.

Esas múltiples parentalidades permiten, igualmente, hablar de diversas parejas. La pareja progenitora representada por los padres biológicos, la pareja conyugal que corresponde a la pareja de esposos o compañeros y la pareja parental que se desempeña

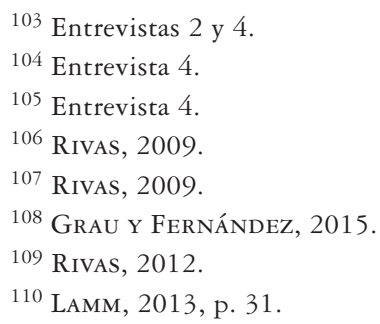


socialmente como los padres sociales de los hijos, es decir, aquellos con quienes se construye maternidad y paternidad ${ }^{111}$.

No obstante, a pesar de esta diversidad parental, la ley solo reconoce dos padres. En ese sentido, la bilateralidad parental se mantiene en Colombia porque el Código Civil continúa determinando la filiación a partir del modelo biogenético y la bilateralidad parental: es madre quien da a luz (artículo 335) y padre quien engendra (artículo 213).

En el caso de las parejas del mismo sexo, la Registraduría Nacional del Estado Civil modificó, en cumplimiento de la sentencia SU-696 de 2015, el registro civil de nacimiento permitiendo que dos padres o dos madres inscriban a sus hijos en ejercicio del principio pro persona, así como del reconocimiento y protección que el Estado debe acordar a las diversas formas de organización familiar ${ }^{112}$.

Si bien la posibilidad de registrar un hijo por las parejas del mismo sexo constituye un avance, el hecho de que el formato del registro civil de nacimiento conserve todavía dos casillas permite deducir la voluntad del legislador y de los jueces de mantener la bilateralidad y de negarse a reconocer abiertamente la existencia de las pluriparentalidades. Si una pareja y el donante o la gestante subrogada desean figurar conjuntamente en el registro civil no hay forma de incluirlos, salvo que se excluya a uno de ellos para ingresar al otro. Este caso ya se presentó en Argentina, donde en abril de 2015 el Registro Provincial de las Personas con sede en Mar del Plata registró al primer niño con tres filiaciones: los dos apellidos de sus madres, unidas en matrimonio, y el apellido de su padre biológico ${ }^{113}$.

Los cambios sociales en materia de diversidad parental exigen una respuesta jurídica, no porque se pretenda que todos los hechos sociales deban ser reglamentados, sino porque la ley está en la obligación de establecer unos criterios orientadores que aseguren la protección y la igualdad de los miembros de cualquier forma de organización familiar.

Una de las entrevistas realizadas contribuyó a comprender cómo se está manejando, en Colombia, el registro en los casos de pluriparentalidades. Debido a que el notario no puede indagar acerca de la forma en la que se produjo la concepción, su función se limita entonces a constatar si la pareja tiene una unión marital de hecho declarada o ha contraído matrimonio. Esto permite aplicar la presunción de paternidad consagrada en el artículo 213 del Código Civil ${ }^{114}$. Si este requisito de forma se cumple, el notario registra como madres a la mujer que aportó el óvulo y a su compañera. De la misma forma se procede en el caso de una pareja de hombres. No obstante, el entrevistado advertía que, en los casos en los que la pareja del mismo sexo no ha contraído matrimonio o no tiene una unión marital declarada, la única opción para que el padre o madre de intención pueda ser reconocido como tal en el registro civil es la adopción del hijo biológico de su pareja ${ }^{115}$.

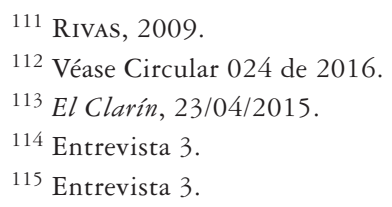




\section{CONCLusiones}

Las TRHA han dado lugar a cambios que cuestionan el modelo biogenético y la bilateralidad parental como elementos tradicionales del parentesco en Colombia. Las alternativas para la reproducción, la mercantilización de la misma, las alternativas para la filiación y la diversidad parental reflejan profundas modificaciones en la forma en que se establece quién es padre, quién es madre y quién es hijo.

La voluntad y el consentimiento deben ser reconocidos como fuente filial, principalmente en los casos en los que las personas o las parejas recurren a las TRHA. Estas nuevas parentalidades deben abordarse dentro de un marco de respeto por la diferencia y la dignidad humana de las personas que construyen y materializan sus proyectos parentales en ejercicio de su autonomía reproductiva.

Ahora bien, el reconocimiento de estos cambios debe hacerse al margen de cualquier patrón o estereotipo respecto de la forma de establecer la filiación. Quienes aplican el Derecho tienen la función de ser justos y objetivos por difícil que parezca. Si bien las concepciones y los discursos no son neutros, cualquier intento por adoptar un marco normativo concerniente al tema debe caracterizarse por su apertura al cambio y una defensa de la diversidad parental.

Las instituciones políticas, jurídicas y sociales tienen el reto de evolucionar a un ritmo similar al que se producen los cambios sociales. El diálogo, la concertación y la escucha activa son elementos fundamentales para facilitar el reconocimiento de estos cambios. Si bien podría considerarse que el control, mediante la prohibición, permite mantener un statu quo, la realidad siempre demostrará que las personas encontrarán la forma de materializar sus decisiones en materia reproductiva. Es necesario entonces reconocer que estas decisiones no son caprichos sino proyectos de vida que merecen el respaldo y la protección del Estado.

\section{BIBLIOGRAFÍA}

Almeling, Rene, 2011: Sex Cells: The Medical Market for Eggs and Sperm, Berkeley: University of California Press.

BAPTISTA, João, 1979: “Desbiologização da paternidade”, Revista da Faculdade de Direito Universidade Federal de Minas Gerais, No 21.

BBC Mundo (1 de septiembre de 2015): UK national sperm bank has just nine donors. Recuperado el 2.12.2017, de BBC: http://www.bbc.co.uk/news/health-34113080.

BBC Mundo (27 de octubre de 2016): UK's national sperm bank stops recruiting donors. Recuperado el 2.12.2017, de BBC: http://www.bbc.com/news/uk-37786576.

Beck-Gernsheim, Elizabeth, 1998: "On the Way to a Post Familial Family", Theory, Culture E Society, volumen 15.

Bestard, Joan, 1998: Parentesco y Modernidad, Barcelona: Paidós.

Bestard, J., Orobitg, G., Ribot., J y Salazar, C, 2003: Parentesco y reproducción asistida: cuerpo, persona y relaciones, Barcelona: Publicaciones Universidad de Barcelona.

Bestard, Joan, 2009: "Los hechos de la reproducción asistida: entre el esencialismo biológico y el constructivismo social", Revista de Antropología Social, vol. 18. 
Buttler, Judith, 2007: El género en disputa, Barcelona: Ediciones Paidós.

Castillo, Carla, 2015: Paternidad activa en sectores urbano-populares de la comuna de Peñalolén: Representaciones sociales sobre paternidades y experiencias de vida vinculadas al género en padres varones de sectores urbano-populares de Peñalolén Alto y Nuevo Peñalolén, activos en la crianza de sus hijos y/o hijas preescolares, Santiago de Chile: Publicaciones Universidad Academia de Humanismo Cristiano.

Código Civil y Comercial de la NaCión, 2014.

Código Civil Colombiano, 1887.

DÉchaux, Jean-Hugues y DARIUs, Mérylis, 2017: "Les familles homoparentales fémenines dans la bioéconocie reproductive", Ethologie française, N No 2017/3.

Delaisi de Parseval, Geneviève y Collard, Chantal, 2007: "La gestation pour autrui: Un bricolage des représentations de la paternité et de la maternité euro-américaines”, L'Homme Revue française d'anthropologie, $\mathrm{N}^{\circ} 183$.

El ClARín (23 de abril de 2015): Entregan por primera vez una partida de nacimiento con tres padres. Recuperado el 2.12.2017, de El Clarín: https://www.clarin.com/sociedad/filiacion-trespadres_0_HybKEsFwXg. Html.

Grau, Claudia y Fernández, María, 2015: "Relaciones de Parentesco en las nuevas familias. Disociación entre maternidad/paternidad biológica, genética y social”, Gazeta de Antropología, volumen 31, $\mathrm{N}^{\circ}$ 1. Disponible en http://www.gazeta-antropologia.es/wp-content/uploads/ GA-31-1-02-ClaudiaGrau_MariaFernandez1.pdf [Fecha de consulta: 2.12.2017].

Hartmann, Heidi, 1981: "La familia como lugar de lucha política de género y de clase: el ejemplo del trabajo doméstico”, en Marysa Navarro y Catherine Stimpson (compiladoras), Cambios sociales, económicos y culturales, México: Fondo de Cultura Económica.

Herrera, Florencia, Miranda, Constanza, Pavicevic, Yanco y Sciaraffia, Valentina, 2018a: "Soy un papá súper normal: Experiencias parentales de hombres gay en Chile", Polis, Revista Latinoamericana, $\mathrm{N}^{\circ} 50$.

Herrera, Marisa, De la Torre, Natalia y Fernández, Silvia, 2018b: Derecho Filial. Perspectiva contemporánea de las tres fuentes filiales, Buenos Aires: Thomson Reuters.

ImAX, Elixabete, 2006: "La maternidad en el seno de las parejas lesbianas: cambios, continuidades y rupturas respecto a los modelos familiares y maternales", Arxius de Sociología, volumen 15.

Inhotn, Marcia y Pasquale, Patrizio, 2009: "Rethinking reproductive 'tourism' as reproductive 'exile", Fertility and Sterility, volumen 92, $\mathrm{N}^{\circ} 3$.

Jociles, María Isabel y Rivas, Ana María, 2014: "Monoparentalidad por elección y revelación de los orígenes a los hijos nacidos por donación de gametos. El caso de España”, Convergencia Revista de Ciencias Sociales, volumen 21, No 65 .

Jociles, María Isabel 2016: Revelaciones, Filiaciones y Biotecnologías. Una etnografía sobre la comunicación de los orígenes a los hijos e hijas concebidos mediante donación reproductiva, Barcelona: Edicions Bellaterra.

JonEs, Christopher \& KeITH, Louis, 2006: "Medical tourism and reproductive outsourcing: The dawning of a new paradigm for healthcare", International Journal of Fertility, volumen $51, \mathrm{~N}^{\circ} 6$.

Kemelmajer, A., Herrera, M., y Lamm, E., 2010: "Filiación y homoparentalidad. Luces y sombras de un debate incómodo y actual”, Revista La Ley.

Kemelmajer, A., Herrera, M., y Lloveras, N., 2014: Tratado de Derecho de Familia (Según el Código Civil y Comercial de 2014), Tomo 2, Santa Fe: Rubinzal-Culzoni.

Kroløkke, Charlotte, Fos, Karen y PANT, Saumya, 2012: "Fertility travel: The commodification of human reproduction”, Cultural Politics, volumen VIII, 2.

KNOPPERS, Bartha y LEBRIS, Sonia, 1991: "Recent advances in medically assisted conception: Legal, ethical and social issues”, American Journal of Law E Medicine, volumen 17. 
LAMM, Eleonora, 2012: “Gestación por sustitución”, InDret, No 3.

LAMm, Eleonora, 2013: Gestación por sustitución: Ni maternidad subrogada ni alquiler de vientres, Barcelona: Publicacions i Edicions de la Universitat de Barcelona.

LÉvi-Strauss, Claude, 1985: Las estructuras elementales del parentesco, Barcelona: Planeta-De Agostini. López, José y ApArisi, Ángela, 2012: “Aproximación a la problemática ética y jurídica de la maternidad subrogada”, Cuadernos de Bioética, $\mathrm{N}^{\circ} 2$.

Maristany, José, 2008: “¿Una teoría queer Latinoamericana?: Postestructuralismo y políticas de la identidad en Lemebel”, Lectures du genre, volumen 4.

Montecino, Sonia, 2007: Madres y huachos. Alegorías del mestizaje chileno, Santiago de Chile: Catalonia.

Morgan, Derek y Lee, Robert, 1998: "What Does Biomedical Diplomacy Mean? Law, Ethics, Risk and the Regulation of Modern Medicine", Fourth World Congress on Bioethics, Tokyo, Japan.

Noel, Martín y Flores, Ana Luisa, 2012: De la filiación inducida a la luz del Código de Familia y Legislación Nicaragüense, Memoria de prueba para optar al grado de Licenciado en la Facultad de Ciencias Jurídicas y Sociales de la Universidad Nacional Autónoma de Nicaragua.

Palacio, María Cristina y Cárdenas, Olga Carolina, 2017: "La crisis de la familia: Tensión entre lo convencional y lo emergente", Maguaré, volumen $31, \mathrm{~N}^{\circ} 1$.

Pennings, Guido, 2002: "Reproductive tourism as moral pluralism in motion", Journal of Medical Ethics, volumen 28, No 6 .

Pesino, Carolina, 2016: Reprogenética, parentalidad homosexual y nuevas familias: análisis de las nuevas estructuras familiares que se plantean a partir de las nuevas técnicas de reproducción bumana (VIII Congreso Internacional de Investigación y Práctica Profesional en Psicología, XXIII Jornadas de Investigación y XII Encuentro de Investigadores en Psicología del MERCOSUR, 23 al 26 de noviembre, Buenos Aires, Argentina).

Pichardo, José Ignacio, 2011: "Sex and the family: intersections between family, gender, reproduction and same-sex sexuality in Spain”, en Judith Takács y Kuhar Roman (cordinadores), Doing families. Gay and lesbian family practices, Liubliana: Mirovni Institut, pp. 17-36.

Pichardo, J. I., DE Stefano, M., y MarTín, L., 2015: “(Des)naturalización y elección: emergencias en la parentalidad y el parentesco de lesbianas, gays, bisexuales y transexuales”, Revista de Dialectología y Tradiciones Populares, volumen 70, $\mathrm{N}^{\circ} 1$.

Puyana, Yolanda, 2003: Padres y madres en cinco ciudades colombianas. Cambios y permanencias, Bogotá: Almudena.

Rivas, Ana María, 2009: "Pluriparentalidades y parentescos electivos”, Revista de Antropología Social, volumen 18.

RIVAs, Ana María, 2012: "El ejercicio de la parentalidad en las familias reconstituidas", Portularia, volumen $12, \mathrm{~N}^{\circ} 2$.

Rivero, Francisco, 1988: "La investigación de la mera relación biológica en la filiación derivada de la fecundación artificial", en Vitoria-Gasteiz (editora), La filiación a finales del siglo XX: problemática planteada por los avances científicos en materia de reproducción bumana, Madrid: Trivium, pp. 141-170.

Romero, Fermín, 2007: "La construcción social de la parentalidad y los procesos de vinculación y desvinculación padre-hijo. El papel del mediador familiar”, Ciencias Psicológicas, volumen $1, \mathrm{~N}^{\circ} 2$.

Rubio, María José, 2012: Gestación por sustitución. La situación de la mujer gestante, Memoria de prueba para optar al grado de máster en Estudios Interdisciplinares de Género de la Universidad de Salamanca.

Sharp, Lesley, 2000: "The Commodification of the Body and Its Parts", Annual Review o Anthropology, volumen 29. 
Schneider, David, 1980: American Kinship: A cultural Account, Chicago: The University of Chicago Press.

ScotTI, Luciana, 2012: "El reconocimiento extraterritorial de la 'maternidad subrogada': una realidad colmada de interrogantes sin respuestas jurídicas", Pensar en Derecho, volumen 1.

STEPTOE, Patrick y EDWARDS, Robert, 1978: "Birth after the reimplantation of a human embryo", Lancet, volumen 11.

VAlls-Llobet, Carmen, 2010: ¿Es necesaria la subrogación de úteros?, en La subrogación uterina: análisis de la situación actual, Barcelona: Fundació Víctor Grífols i Lucas.

VArsi, Enrique y Chaves Marianna, 2010: "Paternidad socioafectiva. La evolución de las relaciones paterno-filiales: Del imperio del biologismo a la consagración del afecto", Actualidad Jurídica, $\mathrm{N}^{\circ} 200$.

VARSI, Enrique, 2017: "Determinación de la filiación en la procreación asistida", Revista IUS, volumen 11, $\mathrm{N}^{\circ}$ 39: Disponible en http://www.scielo.org.mx/scielo.php?script=sci_ arttext\&pid=S1870-21472017000100006\&lng=es\&tlng=es. [Fecha de consulta: 2.12.2017].

Normas jurídicas citadas

LEY 75, 1968: Congreso de la República de Colombia.

LEY 721, 2001: Congreso de la República de Colombia.

LEY 14, 2006: Juan Carlos I Rey de España.

Ley 1098, 2006: Congreso de la República de Colombia.

Circular 024, 2016: Registraduría Nacional del Estado Civil.

Corte Constitucional. Sentencia del 9 de septiembre de 1992. Magistrado Ponente: José Gregorio Hernández Galindo. Sentencia T-512/92.

Corte Constitucional. Sentencia del 12 de noviembre de 2015. Magistrada Ponente: Gloria Stella Ortiz Delgado. Sentencia SU-696/2015 b.

Corte Suprema de Justicia. Sala de Casación Civil. Sentencia del 28 de febrero de 2013. Magistrado Ponente: Arturo Solarte Rodríguez. Sentencia 110013110-002-2006-00537-01.

Corte Suprema de Justicia. Sala de Casación Civil. Sentencia del 10 de mayo de 2017. Magistrado Ponente: Ariel Salazar Ramírez. Sentencia 54001-31-10-009-2009-00585-01. 
